\title{
Kinetic Analysis of Sequencing Batch Reactor for the Treatment of Tannery Wastewater
}

\author{
R.Senthilnathan ${ }^{1}$, Dr. K. Thirumavalavan ${ }^{2}$ \\ ${ }^{1}$ Research Scholar, Dept. of Chemical Engineering, Annamalai University,Annamalai Nagar -608 002., Tamilnadu, \\ ${ }^{2}$ Associate Professor, Dept. of Chemical Engineering, Annamalai University, Annamalai Nagar -608 002, India.
}

\begin{abstract}
In this study, the performance of a bench scale aerobic sequencing batch reactor (SBR) was investigated for the treatment of tannery wastewater. Mixed culture obtained from the activated sludge process treating tannery wastewater was used in the reactor. SBR was operated at different operating conditions by changing the hydraulic retention time (HRT$5,4,3$ and 2 days) and initial substrate concentration (6240mgCOD/L, $4680 \mathrm{mgCOD} / \mathrm{L}, 3220 \mathrm{mgCOD} / \mathrm{L}$ and 1560 $\mathrm{mgCOD} / \mathrm{L})$. From the results it was found that a maximum reduction in COD and color were found to be $84 \%$ and $58 \%$ respectively. In this study, first order and diffusional models are used to describe the kinetics of the degradation of tannery wastewater in SBR. The model parameters were calculated. From the R2 value calculated the first order model fits the data well. In the kinetic studies, modified Stover-Kincannon, Diffusion Model, Michaelis-Menten model and second-order models, and were found to be the most appropriate model for ASBR reacting tannery wastewater than first order model.
\end{abstract}

Key words : Sequencing Batch Reactor (SBR), Chemical Oxygen Demand (COD) Removal, Michaelis- Menten, Second Order, Modified Stover-Kincannon.

\section{INTRODUCTION}

During tanning process at least about $300 \mathrm{~kg}$ chemicals are added per ton of hides[1]. Due to the variety of chemicals added at different stages of processing of hides and skins, the wastewater has complex characteristics. The tanning process and the effluents generated have already been reported in the literature[2-4]. Tanning industry also has one of the highest toxic intensity per unit of output[5]. Tanneries generate wastewater in the range of $30-35 \mathrm{~L} / \mathrm{kg}$ skin/hide processed with variable $\mathrm{pH}$ and high concentrations of suspended solids, BOD, COD, tannins including chromium[6]. Major problems are due to wastewater containing heavy metals, toxic chemicals, chloride, lime with high dissolved and suspended salts and other pollutants [7].
The processes used most frequently for biological treatment of tannery wastewater in CETPs in India are the activated sludge process (ASP) and the upflow anaerobic sludge blanket (UASB) process [8-10]. Biodegradation of tannery wastewater using activated sludge process has been reported by many research workers $[8,11-13]$. Several works have been carried out on tannery wastewater treatment using different reactors [14-18].

Sequencing batch reactor(SBR) is a modification of activated sludge process, which has been successfully used to treat municipal and industrial wastewater. SBR technology has gained more and more importance in wastewater treatment plants[19, 20]. It is known to be a robust system that stands harsh conditions and often been used in order to treat the wastewater from industries[21]. The main advantages are easy operation, low cost, handling hydraulic fluctuation, no need for settling tank and sludge recycling as well as organic load without any significant variation in removal efficiency[22, 23]. The SBR process operates in a series of timed steps, reaction and settling can occur in the same tank, eliminating the need for a final clarifier[24].

\subsection{Model Development}

Mass balance for substrate: feed step

Substrate concentration and reactor fluid content in SBR system are at their respective lowest value at the beginning of feeding. During feeding, the change in waste concentration and the change in reactor waste volume occur simultaneously. A mass balance on waste (accumulation rate $=$ input rateoutput rate- decay rate) gives:

$$
\frac{d(V C)}{d t}=Q C_{0}-0-V_{r}
$$

\subsection{Analysis and Kinetics of the Sequencing Batch Reactors}

Where $Q$ is influent flow rate, $t$ is time; $C$ is waste concentration, $r$ is waste conversion or decay rate, and other terms are as presented in Fig. 1. A list of variables used in this report are presented under nomenclature.

Applying the product rule of differentiation, Equation (1) gives:

$V \frac{d C}{d t}+C \frac{d V}{d t}=Q C_{0}-V_{Y}$ 


$$
\text { or } \quad \frac{d C}{d t}+\frac{C}{V} \frac{d V}{d t}=\frac{Q}{V} C_{0}-r
$$

Knowing that

$$
\frac{d V}{d t}=Q
$$

Equation (2) becomes:

$$
\begin{aligned}
& \frac{d C}{d t}+\frac{C}{V} Q=\frac{Q}{V} C_{0}=r \\
& \text { or } \quad \frac{d C}{d t}=\frac{Q}{V}\left(C_{D}-C\right)-r
\end{aligned}
$$

Observing that $V=V_{0}+V_{\mathrm{t}}$ and that $V_{\mathrm{t}}=Q t$, Equation (3) can be written as in the form:

$$
\frac{d C}{d t}=\frac{Q}{V_{0}+Q t}\left(C_{0}-C\right)-r
$$

Mass balance for substrate: react step

For short feeding time in comparison to react time, we may assume that the reaction time controls waste decay. During the react step, flow into and out of the system are zero. Therefore, Equation (4) gives:

$$
\frac{d C}{d t}=-r \quad \text { or } \quad d t=\frac{d C}{r}
$$

\subsection{Integration Limits}

Waste concentration in the reactor at any time during the feel step $\left(C_{F}\right)$ can be represented by:

$$
\begin{aligned}
C_{F}= & {\left[V_{0} C_{D}+V_{l} C_{0}\right]\left(\frac{1}{V_{0}+V_{l}}\right) } \\
& =\left[V_{R}-V_{D} C_{D}+V_{l} C_{0}\left(\frac{1}{V_{0}+V_{l}}\right)\right]
\end{aligned}
$$

Where $V_{t}$ is the volume of raw waste fed to the reactor at the time of interest, $V_{R}$ is the total reactor volume, and $V_{0}$ is the volume of waste in the reactor at the end of decant $\left(V_{R}-V_{D}\right)$.

The lower integration limit for Equation (5) is the waste concentration at the beginning of react step. It is the waste concentration at the end of feed step $\left(C_{E F}\right)$, and is given by:

$$
\begin{aligned}
\left(C_{E F}\right) & =\left[V_{D} C_{Q}+V_{Q} C_{D}\right]\left(\frac{1}{V_{R}}\right) \\
& =\left[V_{D} C_{Q}+\left(V_{R}-V_{D}\right) C_{D}\right]\left(\frac{1}{V_{R}}\right)
\end{aligned}
$$

The upper integration limit for Equation (5) is the waste concentration at the react step or the decant concentration $\left(C_{D}\right)$. With the integration limits, Equation (5) may be written as:

$$
\begin{aligned}
\int_{0}^{R} d t & =-\int_{\frac{V_{D}}{V_{R}} c_{0}+\frac{V_{R}-V_{R}}{V_{R}} c_{D}}^{C_{D}} \frac{d C}{r} \quad \text { or } \\
t_{R} & =-\int_{\frac{V_{D}}{V_{R}} c_{D}+\frac{V_{R}-V_{D}}{C_{R}} c_{D}} \frac{d C}{r}
\end{aligned}
$$

\subsection{Zero- Order Kinetics}

For zero order reaction kinetics, $r=K$. Therefore, Equation (8) becomes:

$$
\int_{0}^{R} d t=-\int_{\frac{V_{D}}{V_{R}} C_{0}+\frac{V_{R}-V_{D}}{V_{R}} C_{D}} \frac{d C}{k} \quad \text { or }
$$

$$
t_{R}=-\frac{1}{K} \int_{\frac{V_{D}}{V_{R}}}^{C_{D}} c_{0}+\frac{V_{R}-V_{D}}{V_{R}} C_{D} d C
$$

Integrating Equation (9), we have:

$$
\begin{gathered}
t_{R}=-\frac{1}{K}\left[C_{D}-\left(\frac{V_{D}}{V_{R}} C_{Q}+\frac{V_{R}-V_{D}}{V_{D}} C_{D}\right)\right] \\
=-\frac{1}{K}\left[C_{D}-\left(\frac{V_{D}}{V_{R}} C_{0}+\frac{V_{R}}{V_{D}} C_{D}-C_{D}\right)\right]
\end{gathered}
$$

That is:

$$
\begin{gathered}
t_{R}=\frac{1}{K}\left[-C_{D}+\left(\frac{V_{D}}{V_{R}} C_{Q}+\frac{V_{R}}{V_{D}} C_{D}-C_{D}\right)\right] \\
=\frac{1}{K}\left[-C_{D}+\left(\frac{V_{D}}{V_{R}} C_{0}+\frac{V_{R}}{V_{D}} C_{D}-C_{D}\right)\right]
\end{gathered}
$$

That is:

$$
\begin{aligned}
t_{R} & =\frac{1}{K}\left[\left(\frac{V_{D}}{V_{R}} C_{0}+\frac{V_{R}}{V_{D}} C_{D}-2 C_{D}\right)\right] \\
\text { or } K t_{R} & =\left[\left(\frac{V_{D}}{V_{R}} C_{0}+\frac{V_{R}}{V_{D}} C_{D}-2 C_{D}\right)\right]
\end{aligned}
$$

\subsubsection{First- Order Kinetics}

For first order kinetics, $r=K C$. Therefore, Equation (8) becomes:

$$
\begin{aligned}
\int_{0}^{t_{R}} d t & =-\int_{\frac{V_{D}}{V_{R}} c_{0}+\frac{V_{R}-V_{D}}{C_{R}} C_{D}} \frac{d C}{r} \quad \text { or } \\
t_{R} & =-\int_{\frac{V_{D}}{V_{R}} C_{D}+\frac{V_{R}-V_{D}}{V_{R}} c_{D}} \frac{d C}{K C}
\end{aligned}
$$

Integrating equation (13), we have:

$$
\begin{aligned}
t_{R} & =-\frac{1}{K}\left[\ln \ln C_{D}-\ln \ln \left(\frac{V_{D}}{V_{R}} C_{0}+\frac{V_{R}-V_{D}}{V_{D}} C_{D}\right)\right] \\
& =-\frac{1}{K}\left[\ln \ln C_{D}-\ln \ln \left(\frac{V_{D}}{V_{R}} C_{0}+\frac{V_{R}}{V_{D}} C_{D}-C_{D}\right)\right] \\
t_{R} & =\frac{1}{K}\left[-\ln \ln C_{D}+\ln \ln \left(\frac{V_{D}}{V_{R}} C_{0}+\frac{V_{R}}{V_{D}} C_{D}-C_{D}\right)\right] \\
= & \frac{1}{K} \ln \ln \left[\left(\frac{\frac{V_{D}}{V_{R}} C_{0}+\frac{V_{R}-V_{D}}{V_{D}} C_{D}}{C_{D}}\right)\right] \\
t_{R} & =\frac{1}{K} \ln \ln \left[\frac{V_{D}}{V_{R}} \frac{C_{0}}{C_{D}}-\frac{V_{D}}{V_{R}}+1\right] \\
& \text { or } \quad K t_{R}=\ln \ln \left[\frac{V_{D}}{V_{R}} \frac{C_{0}}{C_{D}}-\frac{V_{D}}{V_{R}}+1\right]
\end{aligned}
$$

\subsubsection{Second-Order Kinetics}

For a second order reaction kinetic, $r=K C^{2}$. Therefore, Equation (8) becomes;

$$
\begin{array}{rlr}
\int_{0}^{t_{R}} d t=-\int_{\frac{V_{D}}{V_{R}}}^{C_{D}} c_{D}+\frac{V_{R}-V_{D}}{V_{R}} c_{D} & \frac{d C}{K C^{2}} \\
\text { or } t_{R}=-\frac{1}{K} \int_{\frac{V_{D}}{V_{R}} c_{D}+\frac{V_{R}-V_{D}}{V_{R}} c_{D}}^{C_{D}} & \frac{d C}{C^{2}}
\end{array}
$$

Integrating Equation (17), we have:

$$
\begin{aligned}
t_{R}= & \frac{1}{K}\left[\frac{1}{C_{D}}-\frac{1}{\left(\frac{V_{D}}{V_{R}} C_{0}+\frac{V_{R}-V_{D}}{V_{R}} C_{D}\right)}\right] \\
= & \frac{1}{K}\left[\frac{1}{C_{D}}-\frac{V_{R}}{V_{D} C_{0}+\left(V_{R}-V_{D}\right) C_{D}}\right]
\end{aligned}
$$

That is 


$$
\begin{aligned}
t_{R}= & \frac{1}{K}\left[\frac{\left\lfloor V_{D} C_{D}+\left(V_{R}-V_{D}\right) C_{D}\right]-V_{R} C_{D}}{C_{D}\left[V_{D} C_{D}+\left(V_{R}-V_{D}\right) C_{D}\right]}\right] \\
= & \frac{1}{K}\left[\frac{\left.V_{D} C_{Q}+V_{R} C_{D}-V_{D} C_{D}-V_{R} C_{D}\right]}{C_{D}\left[V_{D} C_{D}+\left(V_{R}-V_{D}\right) C_{D}\right]}\right] \\
t_{R}= & \frac{1}{K}\left[\frac{V_{D} C_{D}-V_{D} C_{D}}{C_{D}\left[V_{D} C_{D}+\left(V_{R}-V_{D}\right) C_{D}\right]}\right] \\
& \text { or } \quad K t_{R}=\left[\frac{V_{D} C_{D}-V_{D} C_{D}}{C_{D}\left[V_{D} C_{D}+\left(V_{R}-V_{D}\right) C_{D}\right]}\right] \\
= & {\left[\frac{V_{D} C_{D}-V_{D} C_{D}}{C_{D}\left[V_{D} C_{D}+\left(V_{R}-V_{D}\right) C_{D}\right]}\right] }
\end{aligned}
$$

\subsection{Grau Second-Order Model}

The second order model was employed to the experimental results for SBR system treating tannery wastewater. The general equation of Grau Second Order Kinetics Model is shown below:

$$
\frac{\mathrm{d} s}{\mathrm{dt}}=k_{2} X\left(\frac{s}{s_{0}}\right)^{2}
$$

Where, $\frac{d s}{d t}$ is the substrate removal rate ( $\mathrm{g} / \mathrm{L}$-day), $\mathrm{k}_{2}$ is kinetic constant (g COD/gVS- day), $\mathrm{X}$ is the concentration of microorganisms $(\mathrm{gVS} / \mathrm{L}), \mathrm{S}$ is substrate concentration at any time, and $S_{0}$ is the concentration of initial substrate $(\mathrm{g} / \mathrm{l})$, integrating the above equation within the boundary conditions $\left(S=S_{i}\right.$ to $S_{e}$ and $t=0$ to $H$ ), and then linearized, the following equation is obtained.

$$
\frac{S_{0} \theta_{H}}{s_{0}-s}=\theta_{H}+\frac{s_{0}}{k_{2} x}-----------(23)
$$

Holding the term " $\frac{s_{0}}{k_{2} X}$ " in the above equation constant leads to

$$
\frac{s_{0} \theta_{H}}{s_{0}-s}=a+b \theta_{H}
$$

The term $\frac{\left[s_{0}-s_{l}\right]}{s_{0}}$ is the substrate removal efficiency $(E)$ and it can be used in the equation as shown below:

$$
\frac{\theta_{H}}{E}=a+b \theta_{H^{-}}
$$

If $V / Q\left(S_{i}-S_{f}\right)$ is plotted against $1 / \mathrm{OLR}, \mathrm{KB} / \mathrm{Umax}$ is the slope and $1 / \mathrm{U}_{\max }$ is the intercept point of the line. Figure 4 shows the plot of the Grau second-order multicomponent model for SBR. The value of $a$ and $b$ were determined from the intercept and slope of the straight lines. The values of $a$ and $b$ were obtained to be 0.87 and 1.019, respectively, with high correlation coefficient $\left(R_{2}=0.99\right)$. This confirms the validity of the application of this model for SBR treating tannery wastewater. Hence, the formula for predicting substrate concentration in the effluent can be given as:

$$
S=S_{0}\left(1-\frac{\theta}{0.87+1.019 \theta}\right)
$$

\subsection{Diffusion Models}

The Diffusional model is given by

$$
\frac{-D C s}{d t}=k D C 0.5
$$

When integrated between the known limits, the above equation becomes

$\sqrt{C s}-\sqrt{C s 0}=-2 k D t$

Where $\mathrm{k}_{\mathrm{D}}=$ Rate constant for Diffusional model From the experimental data, the diffusional model rate constant $\mathrm{k}_{\mathrm{D}}$ was determined through the LSQ fitting. From the $\mathrm{R}^{2}$ values it was found that the diffusional model fails to represent the experimental data. This is clearly depicted.

\subsection{Modified Stover-Kincannon Model}

The Stover-Kincannon was developed first for rotating biofilm reactor (Sandhye and Swaminathan, 2006). It is assumed that the organic loading rate can be correlated with substrate utilization rate using mono-molecular kinetics. The substrate removal rate is defined in two different forms as shown below:

$$
\begin{aligned}
& \frac{d s}{d t}=\frac{Q}{V}(5 i-5 e)-\cdot- \\
& \frac{d s}{d t}=\frac{u \max }{K_{B}}\left(\frac{(Q s i / V)}{\left(\frac{Q 5 i}{V}\right)}\right)-
\end{aligned}
$$

This can be linearlised as

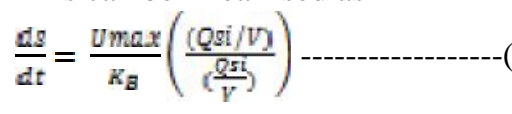

Where ds/dt is the substrate removal rate (g/L-day), $\mathrm{U}_{\max }$ is the maximum utilization rate constant ( $\mathrm{g} / \mathrm{L}$-day), $\mathrm{K}_{\mathrm{B}}$ is saturation value constant ( $\mathrm{g} / \mathrm{L}$-day), $\mathrm{Q}$ is the flow rate (L/day) and $\mathrm{V}$ is the effective volume of reactor (L). Since dS/dt approaches $\mathrm{U}_{\max }$ as the organic loading rate, $\mathrm{qSi} / \mathrm{V}$ approaches infinity.

\section{Materials and methods}

Substrate: The tannery effluent and the mixed culture were collected from the Pallavaram Tannery Effluent Treatment Co. Ltd., Pallavaram, Chennai. India and used as an influent for the bioreactor during the experimental period.

\subsection{Experimental Setup}

Tannery Substrate obtained from Pallavaram Tannery Effluent Treatment plant(Chennai, Tamilnadu) the activated sludge process treating tannery wastewater was used in the reactor[1]. SBR was operated at different operating conditions by changing the hydraulic retention time (HRT- 5,4,3 and 2 days) and initial substrate concentration $(6240 \mathrm{mgCOD} / \mathrm{L}$, 4680mgCOD/L, 3220mgCOD/L and 1560mgCOD/L). Two unique reactors, each with a total volume of 10litre, were used in this research. Rubber tubes were inserted into the reactors to ensure the filling and removal of the tannery effluent using peristaltic pumps. The reactors were supplied with sufficient oxygen by fine bubble air diffuser. The operating conditions in the reactors were maintained at the temperature of $30^{\circ} \mathrm{C}$ (Room Temperature) and $\mathrm{pH}$ of 7 . The mixing inside in our reactors was achieved with a mechanical stirrer at the speed of 150 rpm. Each cycle lasted for 24hours: the filling in 1hour, the reaction took place in 20 hours, the settling in 2 hours, the withdrawal in 0.75 hour and the idle in 0.25 hour as prescribed. The reactors were operated for 50 days for various 
initial concentration of $6240 \mathrm{mg} \mathrm{COD} / \mathrm{L}, 4680 \mathrm{mg} \mathrm{COD} / \mathrm{L}$, $3220 \mathrm{mgCOD} / \mathrm{L}$ and $1560 \mathrm{mg} \mathrm{COD} / \mathrm{L}$ at different $\mathrm{OLR}$, initially $2 \mathrm{kgCOD} / \mathrm{m}^{3}$ day for 15 days followed by $2.5 \mathrm{kgCOD} / \mathrm{m}^{3}$ from the day of $16-30,3.3 \mathrm{~kg} \mathrm{COD} / \mathrm{m}^{3}$ from the day of $31-40$ and finally $5 \mathrm{kgCOD} / \mathrm{m}^{3}$ until the end of the experiment. For this reason the hydraulic retention times in the reactors were maintained as 5,4,3, and 2 days. COD was analyzed by APHA's standard methods for the examination of water and tannery wastewater. In this innovative method, sample was centrifuged at 10,000 rev/min for $30 \mathrm{~min}$ and the $\mathrm{pH}$ was adjusted to 7.8 .

\section{EXPERIMENTAL RESULTS}

These results show that Modified Stover-Kincannon model, First Order Model, Diffusiom Model and Grau Second-Order can be applied successfully for modeling of the experimental results of SBR treating tannery wastewater with high correlation coefficient. On the other hand, the first order model appeared to be less successful $\left(\mathrm{R}^{2}=0.83\right)$ on predicting substrate and color removal from tannery wastewater in SBR system.

Table 1: Kinetic parameter values for the degradation of tannery wastewater in SBR

\begin{tabular}{|c|c|c|c|c|c|}
\hline \multirow{2}{*}{ Kinetic Model } & \multirow{2}{*}{$\begin{array}{l}\text { HRT, } \\
\text { Days }\end{array}$} & \multicolumn{4}{|c|}{ Average Initial Substrate Concentration, mg/L } \\
\hline & & $1560 \mathrm{mg} / \mathrm{L}$ & $3220 \mathrm{mg} / \mathrm{L}$ & $4680 \mathrm{mg} / \mathrm{L}$ & $6240 \mathrm{mg} / \mathrm{L}$ \\
\hline \multirow{4}{*}{$\begin{array}{l}\text { First Order Model } \\
\qquad \mathrm{k} 1, \mathrm{~h}^{-1}\end{array}$} & 5 & 0.1436 & 0.1231 & 0.1128 & 0.0971 \\
\hline & 4 & 0.1204 & 0.1147 & 0.1056 & 0.0836 \\
\hline & 3 & 0.2249 & 0.1932 & 0.1908 & 0.1735 \\
\hline & 2 & 0.0942 & 0.1196 & 0.1392 & 0.1542 \\
\hline \multirow{4}{*}{$\mathrm{R}^{2}$} & 5 & 0.9568 & 0.9519 & 0.9177 & 0.9124 \\
\hline & 4 & 0.9602 & 0.9698 & 0.9017 & 0.8999 \\
\hline & 3 & 0.9195 & 0.9012 & 0.8999 & 0.9000 \\
\hline & 2 & 0.9112 & 0.9001 & 0.9002 & 0.9003 \\
\hline \multirow{4}{*}{$\begin{array}{c}\text { Modified } \\
\text { Stover-Kincannon } \\
\text { Model }\end{array}$} & 5 & 0.5725 & 0.5541 & 0.5435 & 0.6134 \\
\hline & 4 & 0.8254 & 0.8512 & 0.8445 & 0.8614 \\
\hline & 3 & 0.9987 & 0.9957 & 0.9847 & 1.2724 \\
\hline & 2 & 1.4361 & 1.4534 & 1.4523 & 2.0412 \\
\hline \multirow{4}{*}{$\mathrm{R}^{2}$} & 5 & 5.0006 & 4.5805 & 5.0006 & 5.0139 \\
\hline & 4 & 5.0105 & 5.0439 & 5.0402 & 5.0302 \\
\hline & 3 & 5.0668 & 5.0556 & 5.0512 & 5.0515 \\
\hline & 2 & 5.0806 & 5.0695 & 5.0812 & 5.0827 \\
\hline \multirow{4}{*}{$\begin{array}{c}\text { Diffusion Models } \\
\mathrm{kD}, \mathrm{mgCOD} 0.5 / \mathrm{L} 0.5 \mathrm{~h}\end{array}$} & 5 & 1.9153 & 2.5098 & 2.8512 & 2.9583 \\
\hline & 4 & 1.6781 & 2.3566 & 2.6862 & 2.6097 \\
\hline & 3 & 3.1236 & 4.0354 & 4.8516 & 5.2667 \\
\hline & 2 & 2.3262 & 3.0913 & 3.2952 & 3.1495 \\
\hline \multirow{4}{*}{$\mathrm{R}^{2}$} & 5 & 0.9055 & 0.8506 & 0.6535 & 0.7092 \\
\hline & 4 & 0.8628 & 0.8625 & 0.5835 & 0.493 \\
\hline & 3 & 0.2292 & 0.5196 & 0.0015 & 0.0001 \\
\hline & 2 & 0.0754 & 0.3972 & 0.0438 & 0.3017 \\
\hline \multirow{4}{*}{ Grau Second-Order } & 5 & 19.300 & 19.540 & 16.200 & 10.240 \\
\hline & 4 & 24.800 & 25.410 & 24.855 & 17.640 \\
\hline & 3 & 32.700 & 32.640 & 29.810 & 23.140 \\
\hline & 2 & 42.500 & 43.500 & 36.200 & 24.180 \\
\hline \multirow{4}{*}{$\mathrm{R}^{2}$} & 5 & 5.5106 & 5.5422 & 5.4865 & 5.8013 \\
\hline & 4 & 5.5668 & 5.5638 & 5.5528 & 5.8405 \\
\hline & 3 & 6.0033 & 6.0208 & 6.0102 & 5.8915 \\
\hline & 2 & 6.0042 & 6.0215 & 6.0204 & 6.6093 \\
\hline \multirow{4}{*}{$\begin{array}{l}\text { Michaelis-Menten } \\
\text { Model }\end{array}$} & 5 & 0.6215 & 0.5863 & 0.5784 & 0.5834 \\
\hline & 4 & 0.8841 & 0.9221 & 0.8435 & 0.9525 \\
\hline & 3 & 1.4352 & 1.4527 & 1.4421 & 1.3234 \\
\hline & 2 & 1.4358 & 1.4284 & 1.4739 & 2.0547 \\
\hline \multirow{4}{*}{$\mathrm{R}^{2}$} & 5 & 1.1728 & 1.1679 & 1.1337 & 1.1284 \\
\hline & 4 & 1.1762 & 1.1858 & 1.1177 & 1.1159 \\
\hline & 3 & 0.1355 & 0.1172 & 0.1159 & 0.1162 \\
\hline & 2 & 1.1272 & 1.1161 & 1.1162 & 1.1163 \\
\hline
\end{tabular}

The experimental data is compared with the values predicted by first order model. The first order rate constant, $\mathrm{k}_{1}$ was calculated from the slope of the straight line by the least square (LSQ) fit. The rate constants and the determination coefficient 
$\left(\mathrm{R}^{2}\right)$ are presented in Table 2. As the initial concentration of substrate increases, the rate constant $\mathrm{k}_{1}$ decreases. This can be described to a growing importance of the recalcitrant fraction in reducing the diffusivity of the biodegradable substance. The satisfactory values of $\mathrm{R}^{2}$ compliment the ability of the first order model in describing the kinetics of the present work. The determination coefficient $\left(\mathrm{R}^{2}\right)$ is defined as the ratio of explained variance to the total variance. Figure 1-4 shows the fit of the model for the experimental data when the HRT is 5 days.

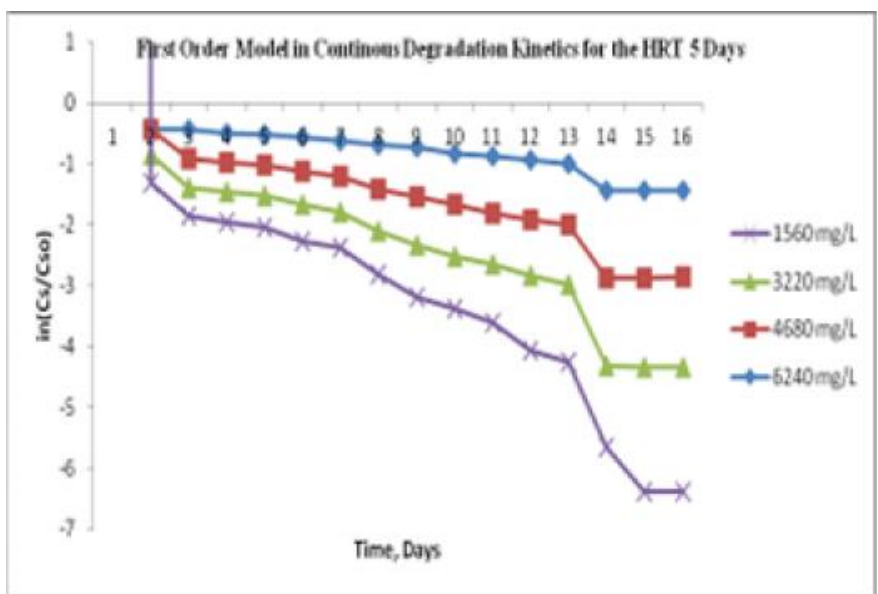

Figure 1: First Order Model in Continous Degradation Kinetics for the HRT 5 Days

The experimental data is compared with the values predicted by first order model in continuous degradation kinetics for the HRT 5 days. The first order rate constant, $\mathrm{k}_{1}$ was calculated from the slope of the straight line by the least square (LSQ) fit. The rate constants and the determination coefficient $\left(R^{2}\right)$ are computed in Table 2. As the initial concentration of substrate increases, the rate constant $\mathrm{k}_{1}$ decreases as in the table. This can be described to a growing importance of the recalcitrant fraction in reducing the diffusivity of the biodegradable substance.

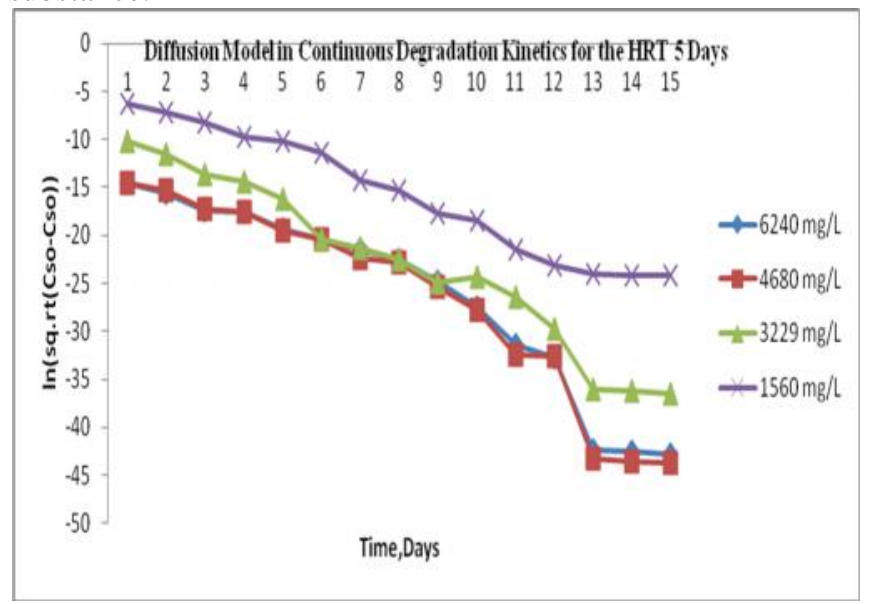

Figure 2: Diffusion Model in Continuous Degradation Kinetics for the HRT 5 Days

From the experimental data, the modified Stover-Kincannon Model in Continuous degradation for the HRT 5 days and rate constant $\mathrm{kD}$ was determined through the LSQ fitting. From the $\mathrm{R}^{2}$ values it was found that the Stover-Kincannon Model fails to represent the experimental data. This is clearly depicted in Figure 3.

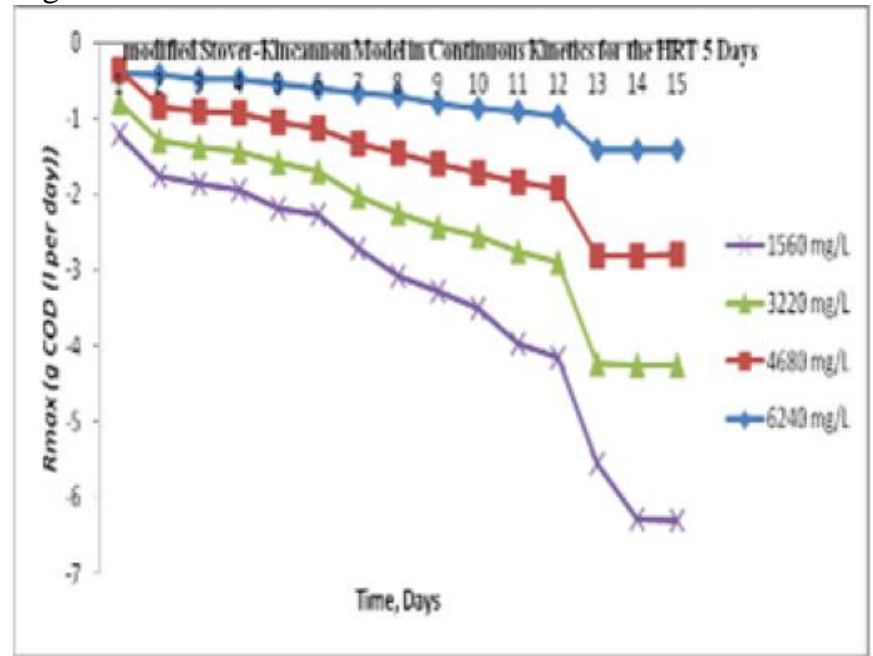

Figure 3: modified Stover-Kincannon Model in Continuous Kinetics for the HRT 5 Days

The experimental data is compared with the values predicted by Michaelis-Menten Model in Continuous Degradation Kinetics for the HRT 5 days. The Michaelis-Menten Model rate constant, $\mathrm{R}_{\max }$ and $\mathrm{K}_{1}$ was calculated from the slope of the straight line by the least square (LSQ) fit. The rate constants and the determination coefficient $\left(\mathrm{R}^{2}\right)$ are computed in Table 2. As the initial concentration of substrate increases, the rate constant $\mathrm{k}_{1}$ decreases as in the table 2 . and fig 3 .

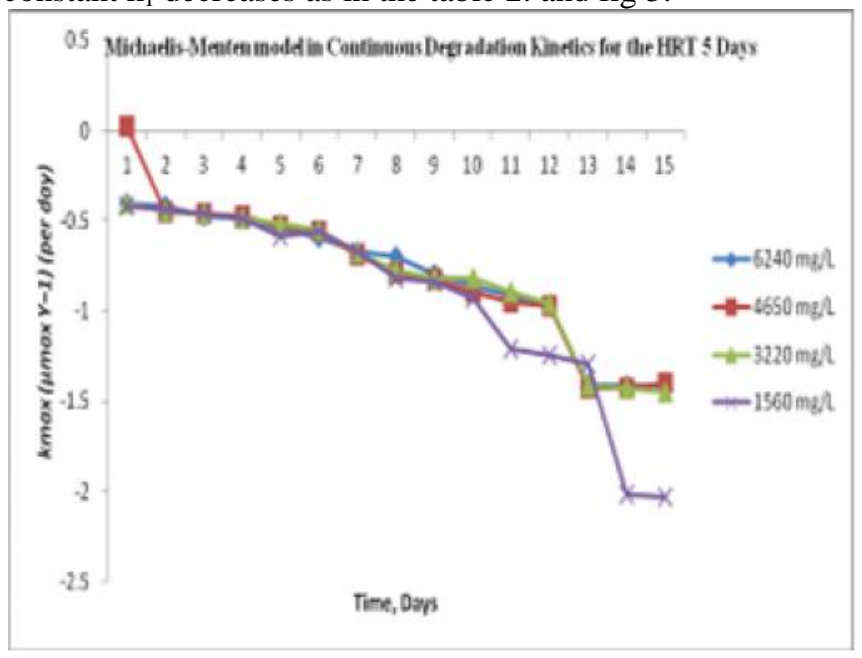

Figure 4 : Michaelis-Menten model in Continuous Degradation Kinetics for the HRT 5 Days

The experimental data is compared with the values predicted by Grau Second Order Model in continuous degradation kinetics for the HRT 5 days. The Grau Second Order Model rate constant, $\mathrm{k}_{\max }$ and $\mathrm{k}_{1}$ was calculated from the slope of the straight line by the least square (LSQ) fit. The rate constants and the determination coefficient $\left(\mathrm{R}^{2}\right)$ are computed in Table 2 . 


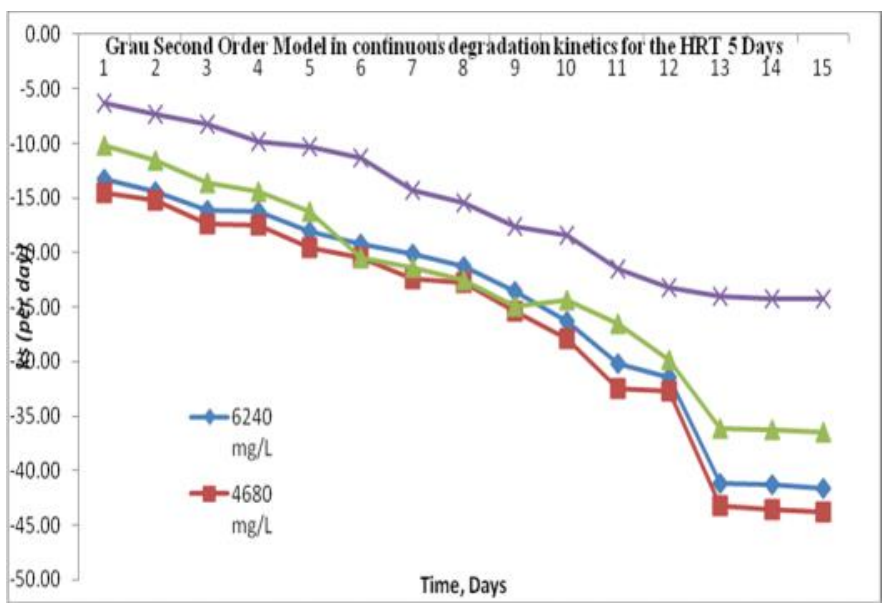

As the initial concentration of substrate increases, the rate constant $\mathrm{k}_{1}$ decreases as in the table 2 . and fig 5 .

\section{COMPARISON OF THE KINETIC PARAMETERS OBTAINED FOR THE VARIOUS SUBSTRATES}

Figure 5 : Grau Second Order Model in continuous degradation kinetics for the HRT 5 Days

Table 2. Comparison of the kinetic parameters obtained for the various substrates.

\begin{tabular}{|l|l|r|r|l|}
\hline \multicolumn{1}{|c|}{ Types of Wastewater } & \multicolumn{1}{c|}{ Reactor } & $\mathbf{U}_{\mathbf{m a x}}$ & $\mathbf{K}_{\mathbf{B}}$ & \multicolumn{1}{c|}{ References } \\
\hline Tannery Wastewater & MSBR & 5.48 & 5.54 & This study(2020) \\
\hline Tannery Wastewater & ASBR & 5.56 & 5.78 & $\begin{array}{l}\text { Andualem Mekonnen et } \\
\text { al(2017) }\end{array}$ \\
\hline Food Processing Wastewater & $\begin{array}{l}\text { Anaerobic } \\
\text { Contact }\end{array}$ & 22.9 & 23.59 & Senturk et al. (2010) \\
\hline Formaldhyde containing & UAFB & 3.4 & 4.6 & Priya et al. (2009) \\
\hline Wastewater & AMBBR & 89.3 & 102.3 & Wanga et al. (2009) \\
\hline Milk Permeate Wastewater & AF & 86.2 & 104.1 & Yilmaz et al.(2008) \\
\hline Paper Mill Wastewater & UAFB & 31.6 & 45.37 & Sandhye et al.,(2006) \\
\hline Textile Wastewater & UASBR & 7.5 & 8.2 & Isik et al.,(2005) \\
\hline Simulated Textile Wastewater & UASBR & 5.3 & 7.05 & Kapdan (2005) \\
\hline Synthetic Saline Wastewater & AF & 3.86 & 0.80 & Ahn et al.,(2002) \\
\hline Corrugated Paper Wastewater & & $p$ & & \\
\hline
\end{tabular}

\section{CONCLUSION}

The continuous degradation of tannery wastewater was carried out in a sequential batch reactor using mixed culture obtained from the tannery sludge. The parameters varied are initial substrate concentration, hydraulic retention time and organic loading rate. The performance of the system proved that the reduction in COD (84\%) and color (58\%) was high in SBR. Decrease in HRT leads to decrease in the percentage COD and color reduction. However significant drops in percentage COD and color reduction occurs for the HRT between 3 and 2 days. It is also observed that there is no significant improvement in the degradation of organic matter above 3 days. From the kinetic studies, it was found that the degradation of tannery wastewater in SBR follows first order model. The kinetic data and rate reaction constants could be used for the design of a field scale SBR for treating tannery wastewater. A design rationale can be evaluated on the basis of present experimental data for the purpose of application of this technology in similar plants. The outcome of the present investigation results would be helpful for making a design rationale for SBR treatment of tannery wastewater and a pilot plant study can be conducted with real-life wastewater sample by application of derived data of present study. In the future scope of the study, microbial genomics study including phosphate removal aspects would be also considered. The influence of Solid Retention Time (SRT) should be explored also. A real-time kinetics profile with automatic data plotting could be derived for explaining the process in more rational way. It is also suggested that optimization of the process and operation variable may be examined with soft computing tools using various statistical approach.

\section{REFERENCES}

1.R. Senthilnathan and K. Thirumavalavan, 2020. Performance Evaluation of Modified Sequencing Batch Reactor (MSBR) For Tannery Effluent Treatment. International Journal of Advanced Research in Engineering and Technology (IJARET) - Scopus Indexed.Volume:11,Issue:7,Pages:317-328.

2. Wiegant WM, Kalker TJJ, Sontakke VN, Zwaag RR. 1999. Full scale experience with tannerywater management: an integrated approach. Water Sci. Technol 39 (5): 169-176. https://doi.org/10.2166/wst.1999.0236 
3. Sreeram KJ, Ramasami T. 2003. Sustaining tanning process through conservation, recovery and better utilization of chromium. Resourc. Conserv. Recycling 38 (3): 185-212.

4. Stoop MLM. 2003. Water management of production systems optimised by environmentally oriented integral chain management: case studyof leather manufacturing in developing countries. Technovation 23 (3): 265-278.

5. Khan SR, Kawaja MA, Khan AM, Ghani H, Kazmi S. 1999. Environmental Impacts and Mitigation Costs Associated with Cloth and Leather Exports from Pakistan. A Report on Trade and Sustainable development Submitted by Sustainable Development Policy Institute and IUCNP to IISD Canada for the IISD / IUCN / IDRC Project on Building Capacity for Trade and Sustainable Development in Developing Countries, Islamabad.

6. Nandy T, Kaul SN, Shastry S, Manivel W, Deshpande CV. 1999. Wastewater management in cluster of tanneries in Tamilnadu through implementation of common treatment plants. Journal of Scientific and Industrial Research 58: 475- 516.

7. Murugesan V, Elangoan R.1994. Biokinetic parameters for activated sludge process treating vegetable tannery waste. Indian J. Environ. Protection 14: 511-515.

8. Durai G, Rajasimman M. 2011. Biological treatment of tannery wastewater: A review. Journal of Environmental Science and Technology 4(1): 1-17.

9. Tare V, Gupta S, Bose P. 2003. Case studies on biological treatment of tannery effluents in India. J. of Air and Waste Management Association 53: 976-982.

10. Haydar S, Aziz JA, Ahmad MS. 2007. Biological treatment of tannery wastewater using activated sludge process. Pak. J. Engg. \& Appl. Sci 1: 61-66.

11. Durai G, Rajamohan N, Karthikeyan C, Rajasimman M. 2010. Kinetics studies on biological treatment of tannery wastewater using mixed culture. International Journal of Chemical and Biological Engineering 3(2): 105-109.

12. Chen Y, He H, Liu H, Li H, Zeng G, Xia X, Yang C. Effect of salinity on removal performance and activated sludge characteristics in sequencing batch reactors. Bioresour Technol. 2018;249:890-899. https://doi.org/10.1016/j.biortech.2017.10.092

13. Moussa M S, Sumanasekera DU, Ibrahim SH, Lubberding HJ, Hooijmans CM, Gijzen HJ, Van Loosdrecht MCM. Long term effects of salt on activity, population structure and floc characteristics in enriched bacterial cultures of nitrifiers. Water Res. 2006;40(7):1377-88.

14. Lefebvre O, Quentin S, Torrijos M, Godon J J, Delgenes J P, Moletta R. Impact of increasing $\mathrm{NaCl}$ concentrations on the performance and community composition of two anaerobic reactors. Appl Microbiol Biotechnol. 2007; 75(1):61-69.

15. Shi K, Zhou W, Zhao H, Zhang Y. Performance of halophilic marine bacteria inocula on nutrient removal from hypersaline wastewater in an intermittently aerated biological filter. Bioresour Technol. 2012;113:280-7.

16. He H, Chen Y, Li X, Cheng Y, Yang C, Zeng G. Influence of salinity on microorganisms in activated sludge processes: a review. Int Biodeterior Biodegradation. 2017;119:520-7.

https://doi.org/10.1016/j.ibiod.2016.10.007 